\title{
The Influence of Different Gingival Thickness on Stress to Implant-Supported Overdenture and Bone
}

\author{
Mohamed I. El-Anwar ${ }^{1}$, Mohamed S. El-Mofty², and Usama M. Fawzy ${ }^{3}$ \\ ${ }^{1}$ Associate Professor, Mechanical Engineering Dept., National Research Centre, Egypt. \\ ${ }^{2}$ Lecturer, Oral Medicine \& Periodontology Dept., Faculty of Dentistry, Ain Shams University, Egypt. \\ ${ }^{3}$ Lecturer, Fixed Prosthodontics Dept., Faculty of Dental Medicine, Al-Azhar University, Assuit, Egypt.
}

\begin{abstract}
This study aimed to evaluate the role of gingival thickness on stress distribution of implants-retained mandibular complete overdenture using finite element method.

A computer aided design (CAD) software and finite element analysis (FEA) software were utilized to construct three dimensional (3D) models on a personal computer to analyze the proposed problem. The three models had different gingival thicknesses ranged 1,2, and 3mm. Unilateral masticatory loads of $150 \mathrm{~N}$ were applied on overdenture in a vertical direction, parallel to the longitudinal axis of the implant, and $45^{\circ}$ oblique. Loads were directed towards the central fossa in the molar region of the overdenture to form six load cases.

Location of maximum Von Mises stress on gingival tissue was found at the model tip close to the load application point where the overdenture and cortical bone squeezed the gingival tissue.
\end{abstract}

Keywords: Finite Element Analysis, Implant supported overdenture, Gingival thickness.

\section{Introduction}

Fabrication of a complete mandibular denture that offers patient comfort, function, and esthetic harmony along with stability and retention remains one of the most challenging procedures in dental practice. Retention or relative lack of sufficient retention of a complete mandibular denture is common, especially when compared with the excellent retention obtained with the maxillary counterpart [1]. In 1988, the NIH Consensus Development Conference on Dental Implants reported that "Among the factors involved in the design of an implant are the force components produced during loading, the dynamic nature of loading, and the mechanical and structure properties of the prosthesis in stress transfer to tissues. Unfortunately, accurate data on such parameters are incomplete [2].

Any attempt to understand the biomechanics and structural properties associated with the dynamic nature of loading must first begin with understanding the load applications in the assembly of the implant complex before the implant functions in the presence of external forces. The implant complex is an assembly of multiple components that form a mechanical screw joint. The forces applied in the assembly process are essential in the maintenance of the functional capacity of the implant system prior to supporting a dental prosthesis. Although the assembly process is well understood, the nature of the forces used to clamp the implant components together and how they are generated and sustained is not [2].

Implant-retained overdenture (IRO) is a removable dental prosthesis that covers and rests on one or more dental implants [3]. The treatment of a fully edentulous mandible by means of IRO has become a routine therapy $[4,5]$. Current techniques employed to evaluate the biomechanical loads over implants generally comprise photoelastic stress analysis, two- or three-dimensional finite element stress analysis (FEA) and strain gauge analysis (SGA) $[2,6]$. Some authors reported that overdentures supported by a two-implant ball system result in a more favorable stress distribution in bone than a two-implant bar system [7]. As a patient uses the implant-retained overdenture, loads are transmitted to the alveolar bone surrounding the implants [8]. For this reason, it is important not to cause excessive loads on the implants because it has been reported that excessive loads may cause bone loss through the induction of bone micro-damage $[9,10]$. In addition, by the difference between the displacement of the implant $(20-30 \mu \mathrm{m})$ and the soft tissue (about $500 \mu \mathrm{m})$ there is stress concentration on the implant, and this stress increases as the resiliency of gingiva increases [11]. IRO depends on support from both the implants and attached gingiva. The gingival thickness of the alveolar ridge of the mandible was observed to be $2.0 \mathrm{~mm}$ on average, with a range of 0.6 to $4.8 \mathrm{~mm}$ [12]. The gingival thickness may affect the denture base displacement during function, therefore the gingival thickness probably influences the stress distribution [13]. Some previous in-vitro studies have indicated the effects of differences in the retentive systems for supported implants with normal soft tissue, but these experiments were performed with only one gingival thickness [14].

Three dimensional FEA has been widely used for the quantitative evaluation of stresses on the implant and its surrounding bone. Some investigators studied the influence of the implant design on stress concentration in the bone during loading and indicated that the implant design was a significant factor influencing the stress 
created in the bone. Others studied the influence of the bone-implant interface on stress concentration. These authors demonstrated that when maximum stress concentration occurs in cortical bone, it is located in the area of contact with the implant and when the maximum stress concentration occurs in trabecular bone, it occurs around the apex of the implant [5].

The aim of the study was directed to numerically compare between different gingival thicknesses, and its effect on stress distribution of implants-retained mandibular complete overdenture.

\section{Materials and Methods}

The current FEA simulates a clinical situation where an edentulous mandible was restored with an implant supported over denture retained by two implants placed at the approximate canine region. Therefore, three simplified models were constructed for the overdenture supported by implant using ball and socket attachment. Similar models were used in other detailed studies $[15,16]$.

All parts of the studied models were drawn in 3D by Autodesk Inventor version 8.0 (Autodesk Inc., San Rafael, CA, USA). Two implants were placed bilaterally in the canine region (22mm apart) vertical to the residual ridge. These implants were retained using resin cement. Prefabricated ball attachments were used to attach the denture base to the two implants, after modification of the denture to accommodate the fixture and attachment. The system analyzed in this investigation consisted of the commonly available root form threaded titanium dental implant (Dentium, Slim Line - Samsung-dong, Gangnam-gu, Seoul, Korea) with ball attachment. The root form dental implant had a nominal diameter of $3.5 \mathrm{~mm}$, a length of $10 \mathrm{~mm}$ one piece as presented in Fig. 1.
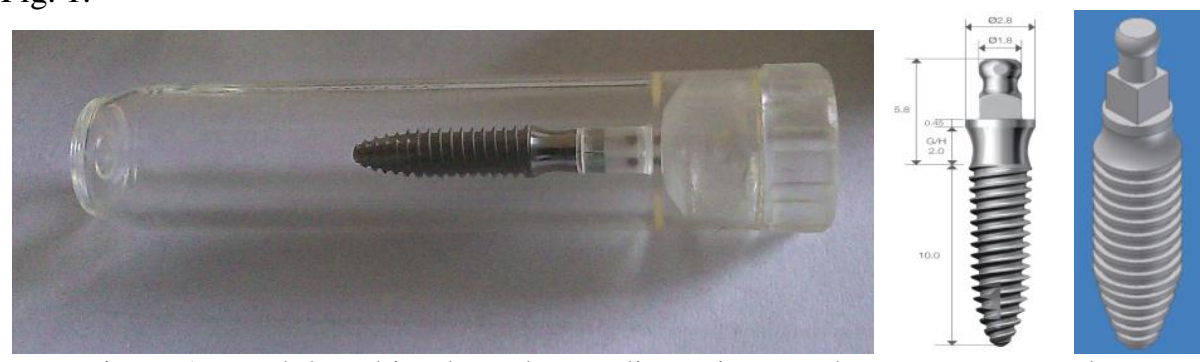

Figure 1: Used dental implant photos, dimensions, and Inventor screen shot

The three dimensional modeled components (overdenture, gingiva, caps, ball and sockets, cortical and cancellous bone) on Autodesk Inventor were exported as SAT files, then imported and assembled in finite element software ANSYS (ANSYS Inc., Canonsburg, PA, USA). Each component has unique physical properties, identifying its behavior under uni-axial loading. These properties assumed to be the same in all directions for homogeneous materials. The used material properties in the current study are listed in Table 1. Meshing of these components by 3D brick solid element (with three degrees of freedom: translations in main axes directions [17]) resulted in huge number of nodes and elements (listed in Table 2).

Table 1: Material properties used in the finite element model

\begin{tabular}{|l|c|c|}
\hline \multicolumn{1}{|c|}{ Material } & Young's modules [MPa] & Posison's ratio \\
\hline Overdenture (Acrylic Resin) & 2,700 & 0.35 \\
\hline Gingiva (1mm) & 680 & 0.45 \\
\hline Gingiva (2mm) & 510 & 0.45 \\
\hline Gingiva (3mm) & 340 & 0.45 \\
\hline Acrylic Cap & 350 & 0.40 \\
\hline Implant complex & 110,000 & 0.33 \\
\hline Rubber Ring & 2,700 & 0.35 \\
\hline Cortical bone & 13,700 & 0.30 \\
\hline Cancellaus (spongy) bone & 1,370 & 0.30 \\
\hline
\end{tabular}

Table 2: Number of nodes and elements in all meshed components in the three models

\begin{tabular}{|c|c|c|c|c|c|c|c|}
\hline & & \multicolumn{2}{|c|}{ Model 1: Gingiva 1mm } & \multicolumn{2}{|c|}{ Model 2: Gingiva 2mm } & \multicolumn{2}{|c|}{ Model 3: Gingiva 3mm } \\
\hline & & $N$ Nodes & N Elements & N Nodes & N Elements & $N$ Nodes & $N$ Elements \\
\hline Part & Name & $\#$ & $\#$ & $\#$ & $\#$ & $\#$ & $\#$ \\
\hline $\mathbf{1}$ & Cortical (base) & 13,251 & 50,787 & 13,251 & 50,787 & 13,251 & 50,787 \\
\hline 2 & Spongy & 17,136 & 66,562 & 17,136 & 66,562 & 17,136 & 66,562 \\
\hline 3 & Implant & 36,453 & 191,634 & 33,815 & 173,673 & 34,708 & 181,737 \\
\hline 4 & Cap & 3,941 & 15,923 & 3,941 & 15,923 & 3,941 & 15,923 \\
\hline 5 & Ring & 660 & 1,895 & 660 & 1,895 & 660 & 1,895 \\
\hline \multirow[t]{3}{*}{6} & Gingiva $1 \mathrm{~mm}$ & 2,169 & 5,556 & & & & \\
\hline & Gingiva $2 \mathrm{~mm}$ & & & 10,952 & 44,726 & & \\
\hline & Gingiva $3 \mathrm{~mm}$ & & & & & 16,063 & 72,982 \\
\hline \multirow[t]{2}{*}{7} & Overdenture & 8,636 & 36,338 & 8,000 & 31,624 & 11,667 & 46,177 \\
\hline & Total & 82,246 & 368,695 & 87,755 & 385,190 & 97,426 & 436,063 \\
\hline
\end{tabular}



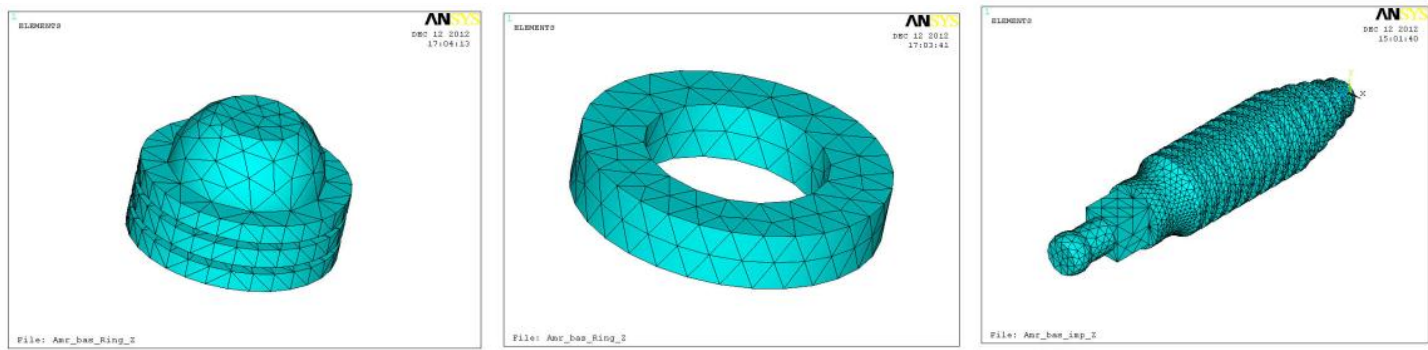

Figure 2: Meshing details of Ball and socket model
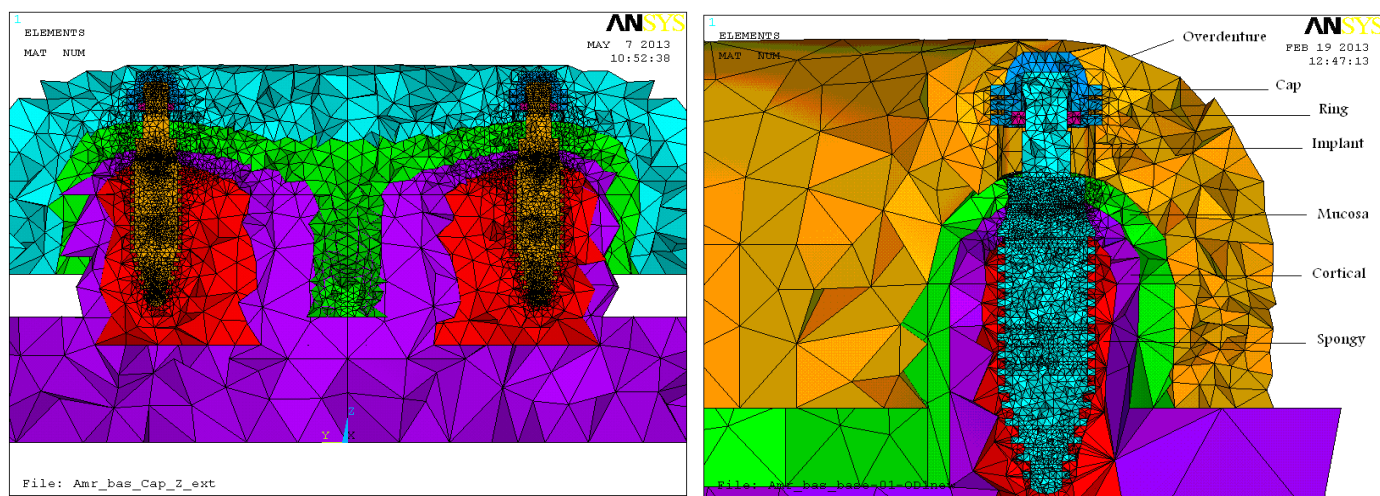

Figure 3: Implant-Ball \& socket, model on ANSYS Screen, showing different components materials (as colors)

Fig. 2 and Fig. 3 showed parts of the meshed models including all components where each component has special physical properties (seen as different colors). Unilateral masticatory (compressive) loads of $150 \mathrm{~N}$ were applied on overdenture, in a vertical direction, parallel to the longitudinal axis of the implant. Another case study was investigated with the $150 \mathrm{~N}$ oblique load of $45^{\circ}$ in lingual-buccal direction, for each gingival thickness to form six case studies. Loads were directed towards the central fossa in the molar region of the overdenture that was tested on the three models. In this research the results of $150 \mathrm{~N}$ are presented graphically as it represented the worst case of overdenture loading. Lowest area was set to be fixed as boundary condition. Linear static analysis was performed on a personal computer (Intel Core to Due processor, $2.8 \mathrm{GHz}, 1 \mathrm{MB}$ cash, 4.0 GB RAM), using commercial multipurpose finite element software package (ANSYS version 9.0).

\section{Results}

The six case studies produced tons of graphically representing pictures of each component of the studied system that extracted from the finite element study. Different deformations and stress distribution on each component of the studied system is presented within this research or tabulated to summarise the results. Maximum Von Mises stress appeared at the neck area of implant whatever the load direction vertical or oblique (as illustrated in Fig. 4, case of $2 \mathrm{~mm}$ gingival thickness under vertical loading). As gingival thickness increase, the maximum Von Mises increases, under oblique loading as indicated in the comparison of the six cases studied. Fig. 4, indicates maximum Von Mises stress in oblique loading conditions are less than vertical loading due to increasing gingival area and energy absorption.
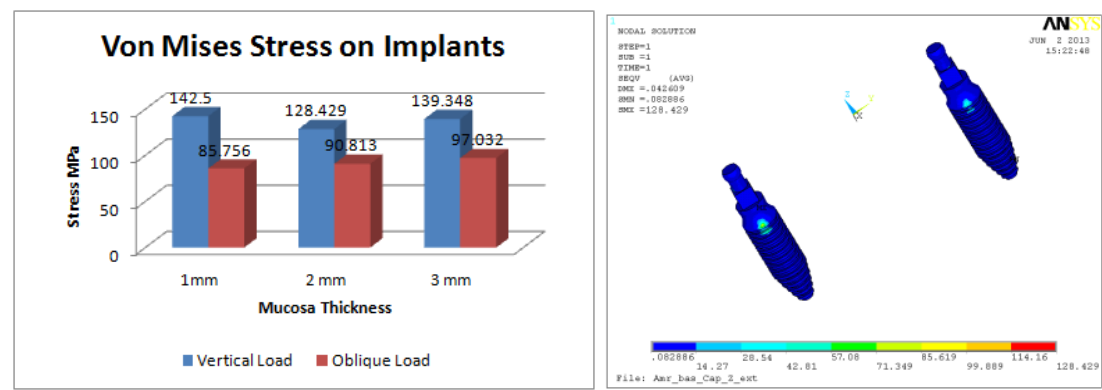

Figure 4: Von Mises stress generated on Implant under $2 \mathrm{~mm}$ gingival thickness and $150 \mathrm{~N}$ vertical loading. 
Spongy bone showed less stresses as the gingival thickness increases. All parts of the studied system specially the gingiva absorbed more energy that resulted in minimizing energy transfer to the spongy bone, as presented in Fig. 5.
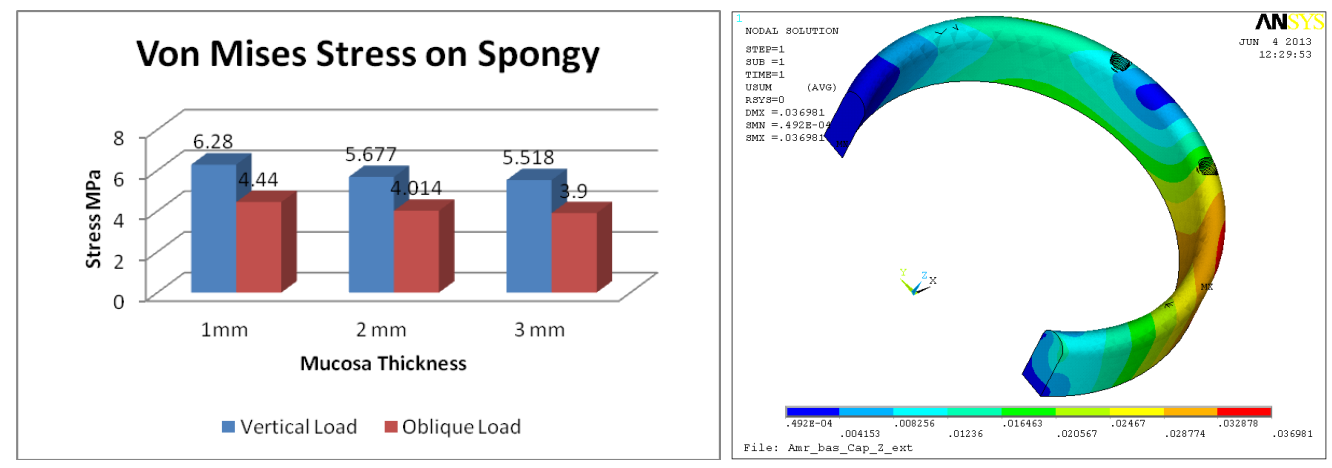

Figure 5: Spongy bone Von Mises stress comparison and total deformation under 1mm gingival thickness and vertical loads of $150 \mathrm{~N}$.

Fig. 6 illustrated the effect of increased gingival thickness on the value of Max Von Mises stress distribution on the cortical bone. Location of Max Von Mises did not change among the six load cases which was the interface area (contact) with implant neck. Von Mises stress range obtained in the six cases studied indicated safe conditions for the cortical bone. Total deformation distribution is also presented in Fig. 6, where the nearest implant to the load location tend to be moving up and the model tip to load location is compressed and showing maximum deformation value.
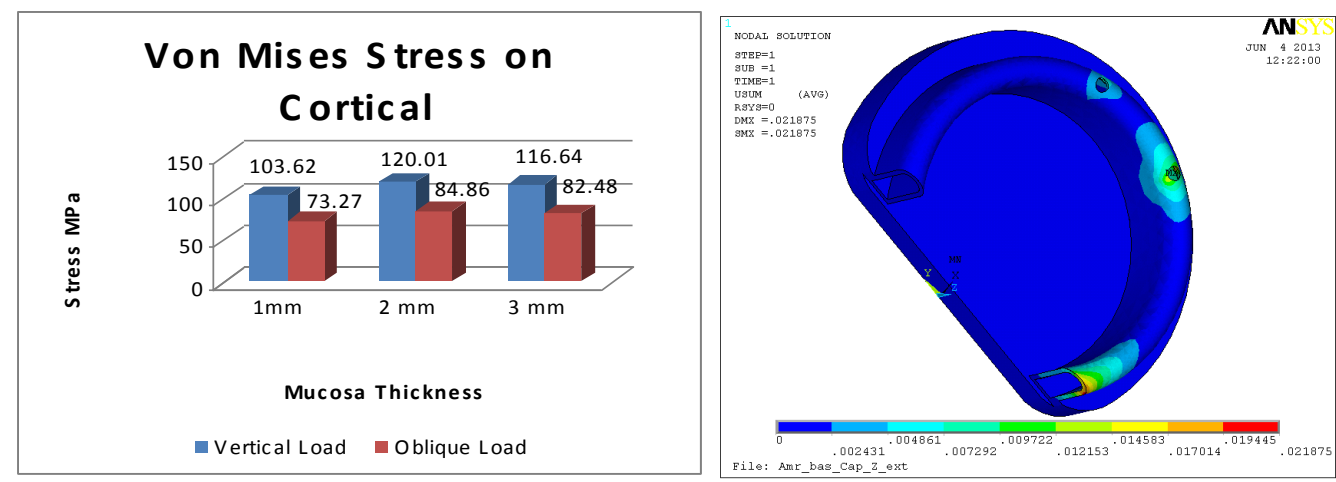

Figure 6: Cortical bone Von Mises stress comparison \& total deformation under 1 $\mathrm{mm}$ gingival thickness and vertical loads of $150 \mathrm{~N}$.
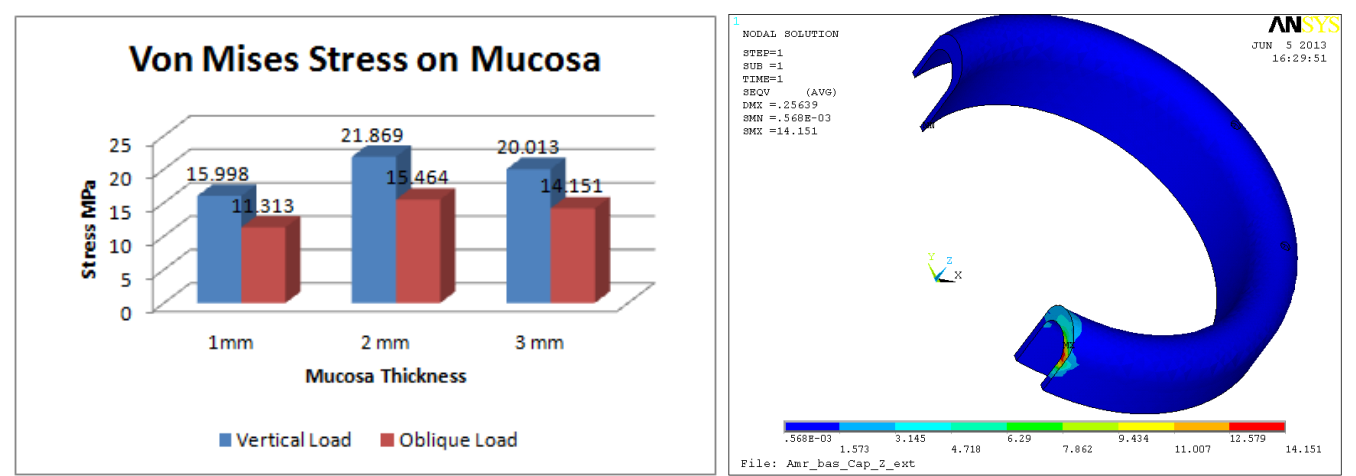

Figure 7: Von Mises stress comparison \& generated on Gingiva under $3 \mathrm{~mm}$ gingival thickness and $150 \mathrm{~N}$ oblique loading

One millimeter gingiva is highly relaxed in comparison to the other two thicknesses. About $30 \%$ increase in Max Von Mises stress (Fig. 7) was noticed in the other two thicknesses, which may be reflected as inflammation due to the gingiva squeezed between jaw bone and overdenture. 
The stresses range in the six case studies, ensure safe and moderate life-time for both caps and overdenture. As gingival thickness increases the expected deformation in caps and overdenture increases, on the other hand Von Mises stress indicates gingival thickness of $2 \mathrm{~mm}$ absorb more energy than the other two thicknesses $(1 \&$ $3 \mathrm{~mm}$ ). Therefore the $2 \mathrm{~mm}$ gingival thickness may enable the longer overdenture life-time, and shorter caps lifetime, as indicated in Fig. 8 and Fig. 9 in terms of maximum total deformation and maximum Von Mises stress values comparisons.
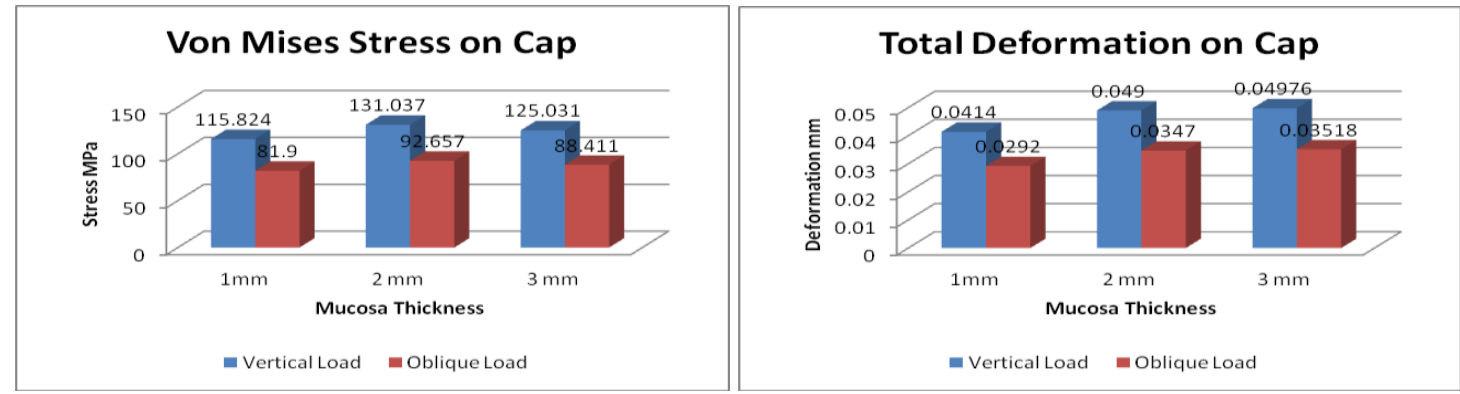

Figure 8: Comparison of Max Von Mises stress, and Max total deformation generated on Caps
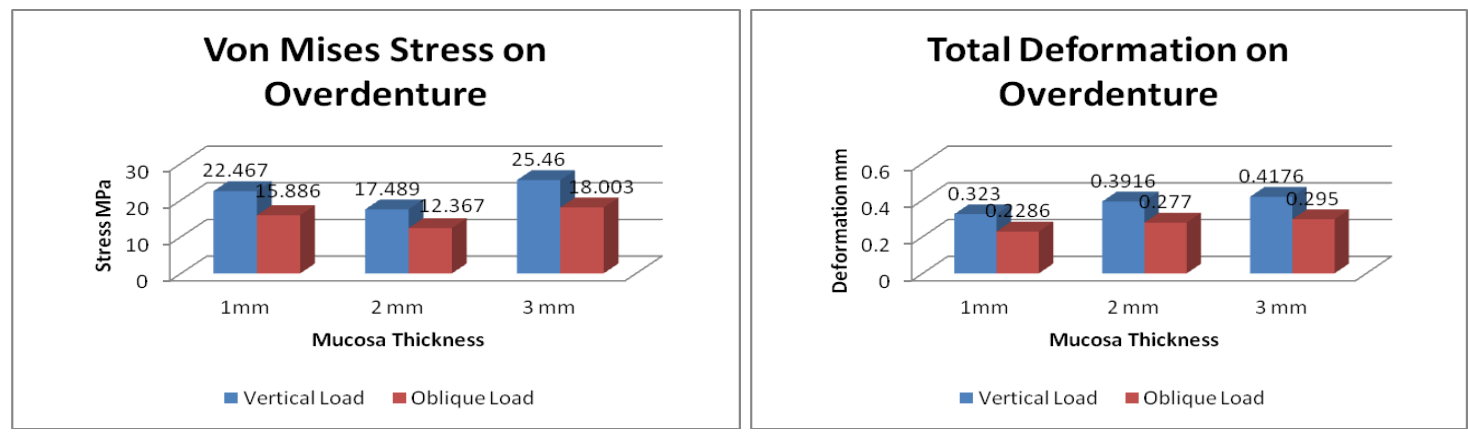

Figure 9: Comparison of Max. Von Mises stress, and Max. total deformation generated on Overdenture

\section{Discussions}

Stress and strain fields around osseointegrated dental implants are affected by a number of biomechanical factors, including the type of loading, material properties of the implant and the prosthesis, implant geometry, surface structure, quality and quantity of the surrounding bone, and the nature of the bone-implant interface. As far as implant shape is concerned, design parameters that primarily affect load transfer characteristics (the stress/strain distributions in the bone) include implant diameter and the length of the bone-implant interface, as well as in the case of threaded implants, thread pitch, shape, and depth. To increase the surface area for osseointegration, threaded implants are generally preferred to smooth cylindrical ones. Depending on bone quality, surface treatments and thread geometry can significantly influence implant effectiveness, in terms of both initial stability and the biomechanical nature of the bone-implant interface after the healing process [18].

The mechanical distribution of stress occurs primarily where bone is in contact with the implant. The density of bone is directly related to the amount of implant-to-bone contact. The percentage of bone contact is significantly greater in cortical bone than in trabecular bone. The initial bone density not only provides mechanical immobilization during healing but also permits better distribution and transmission of stresses from the implant-bone interface. Increased clinical failure rates in poor quality, porous bone, as compared to more dense bone, have been well documented. To decrease stress, the clinician may elect to increase the number of implants or use an implant design with greater surface area [5].

The load transferred to bone through the prosthesis and implant, and careful planning and execution of the prosthetic therapy, are important factors in achieving appropriate stress distribution in the bone. The manner in which bone is loaded may be essential to its response. Bone is usually subjected to cyclic loads, with results that differ from static loads. If a sufficient number of repetitive load cycles are applied, stress microfractures in bone may occur. After bone microfractures occur, microdamage caused by stress greater than normal levels may stimulate osteoclastic activity to remove the damaged bone [13].

Vertical loads from mastication induce axial forces and bending moment and result in stress gradients in the implant as well as in the bone. A key factor for the success or failure of a dental implant is the manner in which stresses are transferred to the surrounding bone. Deflective contacts in the intercuspal position may be responsible for excessive force development. The greatest forces during mastication are exerted in the intercuspal position. If this position is unstable, intolerably high forces could be exerted [19]. 
Discussing the previously demonstrated results should take into account load value and location with respect to implant complex location and attachment type. Loading molar area with fixing implant in canine area will result in complex stress tensor including tensile/compressive, shear, and bending stresses.

Gingival physical properties changed with its thickness that becomes softer (work as cushion). Due to enclosing the gingiva by the overdenture it may behave nonlinearly. Two millimeter gingival thickness may gain higher stresses than the other thicknesses $(1$ and $3 \mathrm{~mm})$. Location of maximum Von Mises stress is located at the model tip close to the load application point where the overdenture and cortical bone squeeze the gingival tissue. In similar study results suggested that the initial modulus as a part of the viscoelastic property is one of the determinant factors of the strain magnitude inside of the soft tissues. The deformation of mucosa is largely a function of fluid interchange with surrounding unstressed mucoperiosteum. The viscoelastic characteristics are attributed to the displacement of blood and tissue elements as well as the distortion of large polymer molecules of the soft connective tissues [20].

The gradual distortion that occurred in the connective tissues indicated that the morphology of the denturesupporting mucosa changes with chewing [21]. It is suggested that duration of the load is a critical factor that causes strain increment near the surface. On the contrary, the maximum strain at the center of mucosa was relatively constant.

The inner mucosa exhibits distinct resistance to deformation under an applied load because of its firm attachment to rigid cortical bone, while the non-rigid surface of the mucosa, without firm support from the bone, exhibits viscous behavior during sustained loading [22]. Meanwhile, the mathematical models, in which the soft tissue is depicted as a homogeneous structure, should be considered in further detail. Inclusion of roles of each tissue component in the models might affect the stress and strain values to some degree. However, the difference in rigidity between tissue components must be considerably smaller than that between the soft tissues and cortical bone, and the model depicted the bottom of the mucosa firmly attached to rigid cortical bone, which is the most influential aspect of the mechanical characteristics of these tissues. Therefore, these facts were significantly more important in the results than the assumed homogeneous structure. However, a structural model consisting of tissue layers with different mechanical properties [23], such as vessels, collagen bundles, and connective tissues, should be developed to account for the roles of each layer in accommodating viscoelasticity. The deformations and physical displacement of loaded oral tissues is thought to be determined by the hydraulic movements of blood and lymph. The lateral hydraulic fluid movements have been reported to be a main determinant for tissue deformations, and are the foundational supports and determinants of movement for prosthetically loaded tissues [24-26]. Although the calculations and component definitions of each of the structure tissues evaluated in this study did not independently separate the lateral components of hydraulic fluid movement mechanics in this study, the estimation maintained overall prior reported measured tissue movement levels under load [27].

In all the studied cases, the stresses were concentrated in the cortical bone around the implant necks which could be explained by the fact that the Young's modulus of cortical bone is higher than cancellous bone and that cortical bone is also stronger and more resistant to deformation.

\section{Conclusions}

For caps and overdenture; as gingival thickness increases, the expected deformation in caps and overdenture increases. The $2 \mathrm{~mm}$ gingival thickness may enable the longer overdenture life-time, and shorter caps life-time.

For Implants; maximum Von Mises stress appeared at neck area of Implant whatever the load direction vertical or oblique. As gingival thickness increase, the maximum Von Mises increases, under oblique loading. Maximum Von Mises stress in oblique loading conditions are less than vertical loading.

Location of Max Von Mises on cortical bone did not change among the six load cases which were the interface area (contact) with implant neck. Stresses on spongy bone will decrease as the gingival thickness increase.

For different gingival thicknesses; Location of maximum Von Mises stress is located at the model tip close to the load application point where the overdenture and cortical bone squeeze the gingival tissue.

\section{Ethical approval}

This research does not require ethical approval and followed the Helsinki declaration.

There is no conflict of interest. 


\section{References}

[1] DD Epstein, PL Epstein, BI Cohen, and MK Pagnillo. Comparison of the retentive properties of six prefabricated post overdenture attachment systems. Journal of Prosthetic Dentistry. 82(5), 1999, 579-584.

[2] EP Holmgren, RJ Seckinger, LM Kilgren, and F Mante. Evaluating parameters of osseointegrated dental implants using finite element analysis - a two dimensional comparative study examining the effects of implant diameter, implant shape, and load direction. Journal of Oral Implantology. 24(2), 1998, 80-88.

[3] MI MacEntee, JN Walton, and N Glick. A clinical trial of patient satisfaction and prosthodontic needs with ball and bar attachments for implant-retained complete overdentures: three-year results. Journal of Prosthetic Dentistry. 93(1), 2005, 28-37.

[4] T Jemt, J Chai, J Harnett, MR Heath, JE Hutton, RB Johns, S McKenna, DC McNamara, D van Steenberghe, R Taylor, RM Watson, and I Herrmann. A five years prospective multicenter follow-up report on overdentures supported by osseointegrated implants. International Journal of Oral \& Maxillofacial Implants. 11(3), 1996, 291-298.

[5] SM Heckmann, W Winter, M Meyer, HP Weber, and MG Wichmann. Overdenture attachment selection and the loading of implant and denture-bearing area. Part 1: In vivo verification of stereolithographic model. Clinical Oral Implants Research. 12(6), 2001, 61723.

[6] R Stegaroiu, T Sato, H Kusakari, O Miyakawa. Influence of restoration type on stress distribution in bone around implants: A threedimensional finite element analysis. International Journal of Oral \& Maxillofacial Implants. 13(1), 1998 Jan-Feb, 82-90.

[7] SJ Sadowsky, and AA Caputo. Effect of anchorage systems and extension base contact on load transfer with mandibular implantretained overdentures. Journal of Prosthetic Dentistry. 84(3), 2000 Sep, 327-334.

[8] G Celik, and B Uludag. Photoelastic stress analysis of various retention mechanisms on 3-implant-retained mandibular overdentures. Journal of Prosthetic Dentistry. 97(4), 2007, 229-235.

[9] JA Porter, VC Petropoulos, JB Brunski. Comparison of load distribution for implant overdenture attachment. International Journal of Oral \& Maxillofacial Implants. 17(5), 2002, 651-662.

[10] K Gotfredsen, T Berglundh, J Lindhe. Bone reactions adjacent to titanium implants subjected to static load of different duration: A study in the dog (III). Clinical Oral Implants Research. 12(6), 2001, 552-558.

[11] T Ichikawa, M Horiuchi, R Wigianto, N Matsumoto. In vitro study of mandibular implant-retained overdentures: the influence of stud attachments on load transfer to the implant and soft tissue. International Journal of Prosthodontics. 9(4), 1996, 394-399.

[12] A Haruta, Y Matsushita, Y Tsukiyama, Y Sawae, N Sakai, and K Koyano. Effects of mucosal thickness on the stress distribution and denture stability of mandibular implant-supported overdentures with unsplinted attachments. Journal of Dental Biomechanics. 2011:894395. doi: 10.4061/2011/894395. Epub 2011 May 26.

[13] T Gonda, K Ikebe, T Ono, and T Nokubi. Effect of magnetic attachment with stress breaker on lateral stress to abutment tooth under overdenture. Journal of Oral Rehabilitation. 31(10), 2004, 1001-6.

[14] M Tokuhisa, Y Matsushita, and K Koyano. In vitro study of a mandibular implant overdenture retained with ball, magnet, or bar attachments: comparison of load transfer and denture stability. International Journal of Prosthodontics. 16(2), 2003 Mar-Apr, $128-134$.

[15] MM Saleh. Stresses distribution of two different attachment designs under implant supported overdenture (Finite Element Study), M.Sc. Thesis, Faculty of Oral and Dental Medicine, Cairo University, 2012.

[16] WS Omar. "Comparative Study of the Stresses Induced in Implant Supported Overdenture By Using Two Different Types of Resilient Attachments (A Three-Dimensional Finite Element Stress Analysis)", M.Sc. Thesis, Faculty of Oral and Dental Medicine, Cairo University, 2012.

[17] P. Kohnke. ANSYS Theory Reference Manual (Ansys Inc., Canonsburg, PA, USA. 1994).

[18] Mohie Eldin HA, Load distribution with different superstructure designs on Osseo-integrated implants. Ph.D. Thesis, Faculty of Oral and Dental Medicine, Cairo University, 1993.

[19] M. Danesh-Meyer. Implant retained mandibular overdentures using locator attachments on endosseous dental implants. Australasian Dental Practice. Mar-April, 2009, 122-124.

[20] RP Scapino. Biomechanics of prehensile oral mucosa. Journal of Morphology. 122 (2), 1967, 89-114.

[21] MA Compagnoni, RF De Souza and CR Leles. Kinesiographic study of complete denture movement related to mucosa displacement in edentulous patients. Pesquisa Odontológica Brasileira. 17(4), 2003, 356-361.

[22] L Fleisch and JC Austin. A histologic study of the response of masticatory and lining mucosa to mechanical loading in the vervet monkey. Journal of Prosthetic Dentistry. 39(2), 1978, 211-216.

[23] F Paulsen and A Thale. Epithelial-connective tissue boundary in the oral part of the human soft palate. Journal of Anatomy. 193(3), $1998 ; 457-467$

[24] M. Kishi. Experimental studies on the relation between area and displacement of loading surfaces in connection with displaceability in the Mucosa of Edentulous Alveolar Ridge under Pressure. Shikwa Gakuho. 72(6), 1972, 1043-1071.

[25] PI Addison. Mucostatic impressions. Journal of the American Dental Association. 31, 1944, 941-946.

[26] M Saito, Y Miura, K Notani, T Kawasaki. Stress distribution of abutments and base displacement with precision attachment —and telescopic crown - retained removable partial dentures. Journal of Oral Rehabilitation. 30 (5), 2003; $482-487$.

[27] R Kanbara, Y Nakamura, KT Ochiai, T Kawai, Y Tanaka. Three-dimensional finite element stress analysis: the technique and methodology of non-linear property simulation and soft tissue loading behavior for different partial denture designs. Dental Materials Journal. 31 (2), 2012, 297-308. 